\title{
Demystifying the Supply of Capital and Labour in a Nation's Economic Chain
}

\author{
Jie Zhou, David Picken \& Chunlu Liu \\ School of Architecture and Building, Deakin University \\ 1 Gheringhap Street, Geelong, VIC 3217, Australia \\ Tel: 61-3-5227-8306 E-mail: chunlu@deakin.edu.au
}

\begin{abstract}
Public capital has been considered to be the wheels of economic activity in a nation or region. The reverse effect, the contribution of economic growth to public capital, is also worth analysis. The non-structural vector auto-regression (VAR) approach is performed for the Australian economy using yearly data for the 1960-2008 period. The optimal lag is investigated to build the VAR model that is then tested for stability. The impulse response function is further employed to examine the response of one economic variable to the innovation of others and to determine the lagged terms for the maximum absolute value of the other variables' responses. The results will provide historical evidence for the federal and regional governments of Australia to estimate the effects of these production variables, in particular, the effect of infrastructure spending on the gross domestic product.
\end{abstract}

Keywords: Capital, GDP, Impulse response function, Labour, Vector autoregression

1. Introduction

Public capital, especially infrastructure, is central to the activities of households and firms, and represents the wheels, if not the engine, of the economic vehicle. Theoretical arguments and historical evidence have shown strong linkages between public capital and economic growth. When the 2008-09 global economic recession was verified, most governments immediately launched infrastructure spending in stimulus packages. For instance, the Australian government planned to spend $\$ 28$ billions out of the $\$ 42$ billions stimulus package, commencing in March 2009, for infrastructure projects and school improvements to lift the country out of a deepening slowdown and to protect against a full-blown recession, which could possibly send the budget into the red for the first time in nearly a decade.

It was not until the late 1980s that economists started to develop quantitative measures of such linkage by building a macro-economic model, pioneered by the economist, David Aschauer (Aschauer 1989). This work inspired an important body of literature particularly on the impact of public capital onto economic growth for other countries as well. Detailed surveys of literature were presented by Gramlich (1994), and Romp and Haan (2007). Under some empirical strategies, the results not only estimated smaller returns to public capital, in comparison with the findings from the pioneering work, but also contradicted the idea of public capital as a productive input. The research results raised several questions that initiated a boom in the study of the effects of public infrastructure on the economy. Although, from a theoretical point of view, few researchers would question that infrastructure has an impact on production, the magnitude of the estimated effect in that seminal paper, was questioned by Gramlich (1994). Furthermore, the aggregate correlation that does not imply any causal relationship between production and infrastructure has been criticised by researchers (Evans and Karras 1994, Holtz-Eakin 1994, Garcia-Mila et al. 1996). One of the most frequently mentioned problems is the spurious correlation between economic growth and endogenous factors. This is because many macro-economic time series demonstrate the characteristic of non-stationarity even though they may trend into similar directions over time in the long-term analysis. If public capital and private production variables are non-stationary, their estimated relationship might be reflecting only a spurious correlation. A more severe critique lies in the actual causal direction of this correlation. The issue is whether public capital increments actually cause economic growth or whether the causality operates in the opposite direction. An alternative research view in the study of this topic is the estimation of models that do not impose any a priori assumption about causality on the data. There have been several examples in the literature, which use econometrics models as an alternative approach to the traditional production function estimations. Besides the flexibility that they offer, an advantage of econometrics models is that they allow testing for the presence of effects between all the variables of interest, even those which may not usually be considered.

The present research takes advantage of non-structural vector auto-regression approaches to examine the response of one economic variable among public capital and gross domestic products (GDP), private capital and labour to the innovation of others. The impulse response function is further used to determine the lagged terms for the maximum absolute value of the other variables' responses for the Australian economy using yearly data for the 1960-2008 period. 


\section{Vector Auto-regression Approaches}

\subsection{Vector Auto-regression Model}

Structural econometrics, especially the simultaneous equation model, was popular during 1950s and 1960s. This model was used to forecast the future development of economic variables. However, the model did not perform well (Hill et al. 2008). Firstly, the simultaneous equation bias problem would led to the correlation of error terms. Secondly, the model was too complicated and hard to determine what is endogenous and what is exogenous. The vector auto-regression model was first developed and introduced to economic research by Sims (1980). It was a breakthrough. The principal of the VAR model is that all variables are jointly determined with no a priori assumptions about causality endogenous or exogenous factors, no zero restrictions and no strict economic theory (Charemza and Deadman 1997). In a VAR model, there are no exogenous variables. Each endogenous variable is explained by its lagged or past value, and the lagged or past value of all other variables. So VAR models allow for testing of whether the causal relationship assumed in other approaches is valid or whether there are reverse feedback effects. Furthermore, the VAR approach allows for testing of indict effects between variables of the model. The standard ordinary least square (OLS) method can be employed to formulate each variable in an unrestricted VAR model. OLS will yield consistent and asymptotically normally distributed estimates even if variables are integrated and possibly cointegrated (Sims et al. 1990). The prediction results obtained by the VAR model perform better than those from the simultaneous equation models (Gujarati 2003). An economic variable not only depends on its current performance but also is related to the past of other variables. The VAR model for $k$ variables with $i$ lagged variable terms can be written as,

$$
B Y_{t}=\sum_{i=1}^{p} A_{i} Y_{t-i}+\varepsilon_{t}, t=1,2,3 \ldots k, i=1,2,3 \ldots p,
$$

where $B$ is a $k^{*} k$ matrix in which the leading diagonal are all $1 ; Y_{t}$ is the $k$ variables symbolised with a k-dimension vector; $A_{i}$ is the number $i k^{*} k$ matrix and $Y_{t-i}$ is the number $i$ lagged variables corresponding to $Y_{t}$; and $\varepsilon_{t}$ is a $k$-dimensional vector of error term.

Normally, the variables in a VAR model are required to be absolutely stationary (Gujarati 2003). They should be transferred to an appropriate form if they are not stationary, such as by first differencing. Otherwise, the VAR model cannot be stable. If the VAR model does not satisfy the stability condition, certain results such as impulse response standard errors are not valid and further implementation will lead to an invalid conclusion (Charemza and Deadman 1997, Gujarati 2003). Some previous studies specified VAR models in levels following the argument that OLS estimates of VAR coefficients are consistent even if the variables are not-stationary and possibly cointegrated (Sims et al. 1990).

One of the biggest practice challenges in VAR is to select the optimal lag order. One of the common approaches in finding the appropriated lag length is to re-estimate the VAR model for all variables from a possible large number of lag lengths (if the data is sufficient enough), then reducing the numbers one by one until zero. The optimal lag order is selected for the VAR model using five criteria. They are Sequential modified likelihood ratio test statistics (LR), Final prediction error (FPE), Akaike information criterion (AIC), Schwarz criterion (SC) and Hannan-Quinn information criterion (HQ). In each of these criteria, the smallest value indicates the optimal lag. However, the five criteria do not always point these to the same number of lag lengths. In this case, several comments can be taken account into. The first is to select a large number as indicated by the five criteria. This can remove the problem of correlation theoretically by adding the lagged variable terms in a VAR model. However, if the numbers of lag lengths are too large, they will distort the data and lead to a decrease in power; and too many parameters in the VAR model make the estimation more complicated and difficult (Dejong et al. 1992). However, a too short lag length in the VAR model may not capture the dynamic behaviour of the variables. Moreover, the judgement of the optimal lag length should still take other factors into account, for example, autocorrelation, hetero-skedasticity, possible ARCH effects and normality and normality of the residuals (Asteriou 2006). It is necessary to be very careful in choosing the optimal lag order especially when the data is insufficient. In practice, the lag at which most criteria reach their lowest values is usually selected to be the optimal lag.

A VAR model with its optimal lag should be tested on stability before the impulse response function is applied. The VAR model is said to be stable if the characteristic roots have a modulus less than one. This is explained in detail by Lütkepohl (2006).

\subsection{Impulse Response Function}

One of the outstanding parts of the VAR model is the impulse response analysis. It presents the dynamic effect of each exogenous variable response to the individual unitary impulse from other variables. A shock of the $i$-th variable not only directly affects the $i$-th variable but is also transmitted to all of the other endogenous variables through the dynamic (lag) structure of the VAR. An impulse response function traces the effect of a one-time shock to one of the innovations on current and future values of the endogenous variables. The impulse response 
function can explain the current and lagged effect over time of shocks in error terms. It estimates the sensitivity of one variable to a change in another one. Taking a VAR(2) model for two variables as an example to illustrate the basic concept of the impulse response function, the VAR(2) model for two variables is formulated as follows

$$
\left\{\begin{array}{l}
X_{t}=a_{1} X_{t-1}+a_{2} X_{t-2}+b_{0} Y_{t}+b_{1} Y_{t-1}+b_{2} Y_{t-2}+\varepsilon_{1 t} \\
Y_{t}=c_{1} Y_{t-1}+c_{2} Y_{t-2}+d_{0} X_{t}+d_{1} X_{t-1}+d_{2} X_{t-2}+\varepsilon_{2 t}
\end{array} \quad t=1,2,3 \quad \ldots\right.
$$

Equation (2) is derived from $E q$. (1), in which $\mathrm{a}_{1}, \mathrm{a}_{2}, \mathrm{~b}_{0}, \mathrm{~b}_{1}, \mathrm{~b}_{2}, \mathrm{c}_{1}, \mathrm{c}_{2}, \mathrm{~d}_{0}, \mathrm{~d}_{1}$ and $\mathrm{d}_{2}$ are coefficients of lagged variables $\mathrm{X}$ and $\mathrm{Y}$. Assume the system starting from $\mathrm{t}=0$ and $X_{t-1}=X_{t-2}=Y_{t}=Y_{t-1}=Y_{t-2}=0$, the error term (at $\mathrm{t}=0) \quad \varepsilon_{10}=1, \quad \varepsilon_{20}=0$ and other $\varepsilon_{1 t}=\varepsilon_{2 t}=0(\mathrm{t}=1,2,3 \ldots)$. The $\varepsilon_{10}=1$ is called the one unit positive standard innovation on $X_{t}$. The response of $X_{t}$ and $Y_{t}$ from $\mathrm{t}=0$ is that $X_{0}=\varepsilon_{10}=1$ and $Y_{0}=0$. Based on the outcomes of $X_{0}$ and $Y_{0}$, when $\mathrm{t}=1$, then $X_{1}=\frac{a_{1}+d_{1} b_{0}}{1-b_{0} d_{0}}, Y_{1}=\frac{d_{1}+a_{1} d_{0}}{1-b_{0} d_{0}}$. Then, the $X_{t}$ and $Y_{t}$ values can be calculated for $\mathrm{t}=2,3$ and others. These calculated values of $X_{0}, X_{1}, X_{2}$ and $\ldots$ are the response to one unit positive standard deviation shock at $\mathrm{t}=1$ from $X_{t}$. Similarly, the values of $Y_{0}, Y_{1}, Y_{2} \ldots$ are the response to one unit positive standard deviation shock at $t=1$ from $X_{t}$.

\subsection{Applications of VAR Models on Public Capital and Economic Growth}

Various empirical studies have used VAR models to assess the impact of public capital on GDP and productivity. The first uncovered journal paper using Vector Auto-regression models to explore the impact of public infrastructure on economic growth was published in 1994 (Mcmillin and Smyth 1994). Since the end of the 1990s, an increasing number of studies have been published and VARs seem indeed to have become the standard time series approach in the public infrastructure-output growth literature, displacing the production function approach, which was more popular in the early 1990s. Among several dozens of articles now available, Prof Alfredo Pereira and his colleagues have made a huge contribution investigating the US and several European countries, including Portugal (Pereira and Andraz 2005, Pereira and Andraz 2006, Pereira and Pinho 2008), Spain (Pereira and Sagales 1999, Pereira and Roca-Sagales 2001) and the USA (Pereira and De Frutos 1999, Pereira 2000).

Based on a summary of VAR studies, the following conclusions were reached by Romp and Haan (2007). Firstly, only a few studies refer to a group of countries, and the rest focus on one or two countries only. Secondly, most studies consist of a four variable VAR model with GDP, employment, private capital and public capital. Thirdly, there is a wide range of model specification in levels or first differences with or without testing cointegration. Fourthly, some studies report that public capital has less impact on economic growth than reported in Aschauer (1989). Finally, many VAR studies report evidence for reverse causality, i.e., feedback from GDP to public capital, in which the long run response of GDP to public capital shock is positive.

\section{Data Description}

For the present research, the annual data of the Australian economy were taken from the Australian Bureau of Statistics (ABS). ABS is an agency of the Australian government and thus its data are considered convincing and the most accurate. The period covered is from 1960 to 2008. The basic variables are public capital stock (G), private capital stock $(\mathrm{K})$, gross domestic product of Australia (Y), and private labour (L).

The three monetary variables are measured in million dollars in their current prices. The time series of public and private capitals and GDP are all taken from the Australian System of National Accounts (ASNA) annually estimated and published by ABS (2009a). The estimates of capital stock and consumption of fixed capital are prepared using the perpetual inventory method (PIM). Estimates of gross capital stock are derived by accumulating past investment flows and by deducting the estimated value of retirements from the stock. Estimates of consumption of fixed capital, and hence net capital stock, are derived using a depreciation function based on the expected economic life of the various assets. The ASNA forms a body of statistics that incorporates a wide range of information about the Australian economy and its components. In addition to the long-standing statistics of national income, expenditure and product, the accounts include the financial accounts, input-output tables, balance sheet statistics (including capital stock statistics), multifactor productivity statistics, and State accounts.

The labour data are drawn from the ABS monthly document Labour Force, Australia (ABS 2009b). This publication contains estimations of the civilian labour force derived from the Labour Force Survey component of the Monthly Population Survey that comprises the Labour Force Survey and one or more supplementary surveys and is conducted by the ABS staff. The estimation method used in the labour force survey is composite estimation, which combines data collected in the previous six months with the current month's data to produce 
the current month's estimates, thereby exploiting the high correlation between overlapping samples across months in the labour force survey. The composite estimator combines the previous and current months' data by applying different factors according to length of time in the survey. After these factors are applied, the seven months of data are weighted to align with the current month population benchmarks. The labour is measured as the number of employees in thousands.

Before data are pooled into the analytical models, all four variables are transformed into their natural logarithms to stabilise the variances and to normalise their distributions.

\section{Constructing the Vector Auto-regression Model}

The Eagle-Grange test has detected the causal relationships between public capital and economic growth in Australia. However, it does not trace the response of one economic variable to the shocks of others. In the present research, the vector auto-regression model is constructed to investigate the impulse response function. The VAR model does not satisfy the stability condition in levels and therefore all economic variables after the first difference are used to construct the VAR model. There are at least two advantages when using the first difference data series to explain the impulse response function. First, it focuses more on the increase or decrease trend rather than the actual values of economic variables. Because the first difference data series is the increase or decrease between every two conterminous quarters, the strengthening or weakening on the trend will be detected by the impulse response function. Second, it catches more information on the shocks of economic variables because the first difference data shows the changes in the past two quarters while the level shows one in impulse response function.

\subsection{Selection of Optimal Lag}

Table 1 presents the results of VAR lag order selection using the five criteria mentioned above. The first left hand column shows the lag orders from 0 to 4 . The numbers with asterisk are the smallest value in each of the criteria. Lags one and two are the only two choices. Considering that lag one is too short to capture the dynamic behaviour of the variables, two lags (two quarters in time) are selected to be the optimal lag length in the VAR(1) model. Apparently, this lag is not long enough to distort the data or even to lead to a decrease in power.

\subsection{Stability Test of the VAR Model}

The stability of the VAR model with its optimal lag should be verified prior to the application of the model into the implementation. This step is very important for the results of the impulse response function. If the VAR model does not satisfy the stability condition, certain results such as impulse response standard errors are not valid. The stability is achieved if the characteristic roots of the matrix of coefficients have a modulus of less than one. Table 2 shows the results of the roots of characteristic polynomial. The results show that all roots are less than 1 and no root lies outside the unit circle. This indicates that the VAR(1) model satisfies the stability condition. So the results of impulse response function derived from the VAR(1) are valid in our study.

\section{Impulse Responses among Economic Variables}

\subsection{Impulse Response}

Figure 1 shows the impulse response results of the four economic variables in four fractional graphs respectively. It traces out the response of each economic variable in VAR(1) model to the shocks in the error terms of all variables. The horizontal axis shows the study window of 20 quarters and the vertical axis shows the shock in the trend.

Three among the four curve lines in each fractional graph start from zero in time 1, and each fractional graph embodies the impulse responses of that economic variable with non-zero starting value in time 1 . In other words, only one economic variable is assumed to have a non-zero response to its past shock and the other variables are assumed to receive a one positive unit standard deviation shock from other variables in the first quarter. For instance, the first fractional graph shows the effect of a shock to labour on the time-paths of labour, GDP, public capital and private capital. A positive symbol in the figure does not mean an increase in economic variables, but it does mean that the increase trend is strengthened or the decrease trend is weakened. In the same way, a negative symbol means the increase trend is weakened or the decrease trend is strengthened. In short, a positive symbol means a favourable effect on the growth of the economic variable and a negative symbol means an adverse effect. In addition, the value shown in the figure indicates a change on the movement trend of each economic variable. The results of the impulse response function indicate that the biggest reactions of an economic variable to the economic variable shock take place after one or two quarters. This may be considered an immediate response considering the complexity of the nation's economy.

The impulse response results raise several interesting findings. The important influence on the response of an economic variable is its past performance rather than other variables. Both public capital and private capital received stronger positive impact from the past performance of themselves than labour and GDP. Furthermore, each economic variable was influenced more by the GDP and public capital compared to the other two. In addition, the influence on the four variables by private capital is obviously weaker than that by public capital. Therefore, public capital among the four economic variables causes the most significant impulse responses of all 
variables and it may be concluded that the most powerful and sensitive variable in the Australian economy is public capital. This conclusion, however, does not denote that public capital is the epicentre.

Table 3 summarises the total impulse responses of all economic variables in 20 lagged quarters, which are generated from the results of the impulse responses presented in Figure 1. The bold numbers on the diagonal line describe the impulse response of each variable to the innovation of itself. These numbers are the largest in each row. The results suggest that the most important factor for each economic variable is from the past individual performance of itself.

Furthermore, some economic variables have negative effects on others even if the positive changes exist in the movement trend in the whole time period. Both public capital and private capital exhibit a reverse impact on the other two variables, labour and GDP, which indicates the differences of the long run relationships among these variables, and so do the effects of labour and GDP on private capital. Only public capital among these four variables shows a positive response to all economic variables, i.e. all economic variables have a positive influence on public capital. The response of public capital to labour is even bigger than the response of labour to itself. The high sensitive values of public capital to all economic variables indicate that public capital was normally used as an immediate response of the government to the change of economy regardless of labour, capital or gross domestic product. However, no economic variable shows the largest response to public capital from the long term viewpoint, except for itself, although the above shows that public capital is the most powerful variable. This signifies that public capital is not the main engine in the movement trends of economic variables in Australia. Public capital seems a constant current regulator to stabilise the economy as its role takes effects more passively not positively.

\subsection{Lagged Effect of Economic Variable Diffusion}

The values of response to the innovation perform a kind of behaviour which converges almost to zero (not exactly at zero) first and then swings around zero in the long run. It can be concluded that the influence from each of the economic variables on a certain variable will last for the long-run but the influence will weaken gradually. The speed of convergence to zero can scale the sensitivity of one variable to the influence from others. In this study, 0.005 and 0.001 of absolute value are set up as two standards to measure this speed. Table 4 shows the numbers of lagged terms when each variable first reaches a value of impulse response of less than 0.005 or 0.001 .

Most of the numbers to labour are greater than the others located in the same row. This indicates that the influence from labour on other economic variables will persist over a longer period. This proves that labour is an important factor in the aggregate Australian economy. Unlike the public capital discussed above, labour is a positive economic variable which takes an active, strong and long effect in the Australian economy. A small number of the lagged term indicates that the influence disappears quickly. Responses of labour and GDP have relatively smaller lagged terms compared to the responses of public capital and private capital. This denotes that the impact either from themselves or from exogenous variables cannot persist for a long time. In other words, the convergence speeds of labour and GDP are faster than those of public capital and private capital. Considering the relatively small impulse responses of labour and public capital to themselves, these two variables inactively react to the innovation of economic vibration. The responses of public capital and private capital are more sensitive to changes of economic variables.

Furthermore, the numbers of lagged terms shown on the diagonal line in Table 4 explain the time intervals of economic variables affected by themselves. Interestingly enough, these numbers are not the largest in several rows except that the diagonal numbers in rows "response of labour to" and "response of GDP to" are the largest for significance 0.005 . It should be noted that these two largest numbers in rows are not the largest number in the table. Even more interestingly, the response of public capital to itself has the smallest value for either 0.005 or 0.001. In addition, the responses of economic variables to labour are relatively long in most rows in Table 4 . This is followed by the responses of economic variables to private capital. The largest lagged terms are 6 and 10 quarters for significances 0.005 and 0.001 respectively, and both are the responses of public capital and private capital to the labour variable.

Figure 2 shows the numbers of lagged terms given in Table 4 in two fractional graphs for first reaching the value of impulse response of less than 0.005 and 0.001 respectively. There are four quadrilaterals with the same centre ( 0 of lagged term). Each quadrilateral shows the sensitivity of one economic variable to the four variables. The greater the quadrilateral area is, the more sensitive the variable is. Similar to the results discussed above, the areas of responses of public capital and private capital are obviously bigger than those of labour and GDP. The marks on the labour lines in two fractional graphs are relatively bigger than those on other lines.

\subsection{Effect of Innovation}

Figure 3 shows the effect of one standard deviation innovation starting from each economic variable. It is derived from the VAR(1) impulse response function presented in Figure 2. It can point out the response and impacts of an economic variable from another angle although no new information or knowledge is further shown in addition to the above explanations. This figure indicates that the effects of labour drastically fluctuate within 
the initial eight quarters, which signifies that the change of labour may evidently affect the changes of economic variables in the two year period. The effects of GDP and private capital follow those of labour. The effects of public capital are most stable and its convergence speeds are also the fastest among all four economic variables.

\section{Conclusions}

This research applies a non-structural vector auto-regression approach to the Australian economy using yearly data for the 1960-2008 period. The optimal lag is investigated to build a four variable VAR model with labour, GDP, public capital and private capital, and the model is then tested for stability. The impulse response function is further employed to examine the response of one economic variable to the innovation of others and to determine the lagged terms for the maximum absolute value of the other variables' responses. The following conclusions can be stated:

(1) The results of the impulse response function indicate that the biggest reactions of an economic variable to an economic variable shock quickly take place after one or two quarters. The most significant factor affecting each economic variable is its own individual performance in the past.

(2) Public capital is considered to be the most powerful and sensitive variable in the Australian economy. Public capital is, however, not the main wheel driving the movement of economic variables in Australia. Public capital, which is more like a constant current regulator, is passively used to stabilise the economy.

(3) Labour is a positive economic variable which has an active, strong and long-term effect on the Australian economy. The change of labour evidently affects the changes of economic variables in approximately two years.

\section{References}

ABS. (2009a). Australian System of National Accounts. Australian Bureau of Statistics, Canberra.

ABS. (2009b). Labour Force, Australia, Australian Bureau of Statistics, Canberra.

Aschauer, D. A. (1989). Is Public Expenditure Productive? Journal of Monetary Economics, 23(2), 177-200.

Asteriou, D. (2006). Applied Econometrics: A Modern Approach Using Eviews and Microsoft, Palgrave Macmillan, New York.

Charemza, W. \& Deadman, D. (1997). New Directions in Econometric Practice : General to Specific Modelling, Cointegration, and Vector Autoregression, Edward Elgar Pub., Lyme, N.H.

Dejong, D. N., Nankervis, J. C., Savin, N. E. \& Whiteman, C. H. (1992). The Power Problems of Unit Root Test in Time Series with Autoregressive Errors. Journal of Econometrics, 53(1-3), 323-343.

Evans, P. \& Karras, G. (1994). Are Government Activities Productive? Evidence from a Panel of U.S. States. The Review of economics and statistics, 76(1), 1-11.

Garcia-Mila, T., Mcguire, T. J. \& Porter, R. H. (1996). The Effect of Public Capital in State-Level Production. Review of Economics \& Statistics, 78(177-180.

Gramlich, E. M. (1994). Infrastructure Investment: A Review Essay. Journal of Economic Literature, 32(3), 1176-1196.

Gujarati, D. N. (2003). Basic Econometrics, McGraw Hill, Boston.

Hill, R. C., Griffiths, W. E. \& Lim, G. C. (2008). Principles of Econometrics, Wiley, Hoboken, NJ.

Holtz-Eakin, D. (1994). Public-Sector Capital and the Productivity Puzzle. The Review of economics and statistics, 76(1), 12-21.

Lütkepohl, H. (2006). New Introduction to Multiple Time Series Analysis, Springer, Berlin.

Mcmillin, W. D. \& Smyth, D. J. (1994). A Multivariate Time Series Analysis of the United States Aggregate Production Function. Empirical Economics, 19(659-673.

Pereira, A. \& Pinho, M. (2008). Public Investment and Budgetary Consolidation in Portugal. Portuguese Economic Journal, 7(183-203.

Pereira, A. \& Sagales, O. R. (1999). Public Capital Formation and Regional Development in Spain. Review of Development Economics, 3(281.

Pereira, A. M. (2000). Is All Public Capital Created Equal? Review of Economics \& Statistics, 82(513.

Pereira, A. M. \& Andraz, J. M. (2005). Public Investment in Transportation Infrastructure and Economic Performance in Portugal. Review of Development Economics. Blackwell Publishing Limited.

Pereira, A. M. \& Andraz, J. M. (2006). Public Investment in Transportation Infrastructures and Regional Asymmetries in Portugal. Annals of Regional Science, 40(803-817.

Pereira, A. M. \& De Frutos, R. F. (1999). Public Capital Accumulation and Private Sector Performance. Journal of Urban Economics, 46(2), 300-322.

Pereira, A. M. \& Roca-Sagales, O. (2001). Infrastructures and Private Sector Performance in Spain. Journal of Policy Modeling, 23(4), 371-384. 
Romp, W. \& Haan, J. (2007). Public Capital and Economic Growth: A Critical Survey. Perspektiven der Wirtschaftspolitik, 8(Special Issue), 6-25.

Sims, C. A. (1980). Macroeconomics and Reality. Econometrica, 48(1), 1-48.

Sims, C. A., Stock, J. H. \& Watson, M. W. (1990). Inference in Linear Time Series Models with Some Unit Roots. Econometrica, 58(1), 113-144.

Table 1. VAR lag order selection criteria

\begin{tabular}{|l|l|l|l|l|l|l|}
\hline Lag & LogL & LR & FPE & AIC & SC & HQ \\
\hline $\mathbf{0}$ & 133.9222 & NA & $3.65 \mathrm{e}-08$ & -5.774319 & -5.613726 & -5.714452 \\
\hline $\mathbf{1}$ & 395.9877 & 465.8943 & $6.52 \mathrm{e}-13$ & -16.71056 & $-15.90760^{*}$ & $-16.41123^{*}$ \\
\hline $\mathbf{2}$ & 413.2284 & $27.58507^{*}$ & $6.29 \mathrm{e}-13^{*}$ & $-16.76570^{*}$ & -15.32037 & -16.22690 \\
\hline $\mathbf{3}$ & 423.0868 & 14.02096 & $8.65 \mathrm{e}-13$ & -16.49275 & -14.40505 & -15.71448 \\
\hline $\mathbf{4}$ & 435.5969 & 15.56812 & $1.10 \mathrm{e}-12$ & -16.33764 & -13.60757 & -15.31990 \\
\hline
\end{tabular}

* indicates lag order selected by the criterion

LR: sequential modified likelihood ratio test statistic (each test at $5 \%$ level)

FPE: Final prediction error

AIC: Akaike information criterion

SC: Schwarz information criterion

HQ: Hannan-Quinn information criterion

Table 2. VAR roots of characteristic polynomial

\begin{tabular}{|l|l|}
\hline Root & Modulus \\
\hline 0.987174 & 0.987174 \\
\hline $0.830367-0.121073 \mathrm{i}$ & 0.839148 \\
\hline $0.830367+0.121073 \mathrm{i}$ & 0.839148 \\
\hline $0.610419-0.358882 \mathrm{i}$ & 0.708101 \\
\hline $0.610419+0.358882 \mathrm{i}$ & 0.708101 \\
\hline $0.272857-0.258146 \mathrm{i}$ & 0.375620 \\
\hline $0.272857+0.258146 \mathrm{i}$ & 0.375620 \\
\hline-0.247938 & 0.247938 \\
\hline
\end{tabular}

Table 3. Total impulse response in 20 lagged term

\begin{tabular}{|l|l|l|l|l|}
\hline & Labour & GDP & Public capital & Private capital \\
\hline Response of labour to & $\mathbf{0 . 0 1 6 3}$ & 0.0034 & -0.0016 & -0.0081 \\
\hline Response of GDP to & 0.0008 & $\mathbf{0 . 0 2 1 5}$ & -0.0057 & -0.0193 \\
\hline Response of public capital to & 0.0167 & 0.0142 & $\mathbf{0 . 1 0 5 0}$ & 0.0036 \\
\hline Response of private capital to & -0.0141 & -0.0079 & 0.0152 & $\mathbf{0 . 0 7 9 5}$ \\
\hline
\end{tabular}

Table 4. Lagged term when first reaching a value of impulse response

\begin{tabular}{|l|l|l|l|l|l|}
\hline \multicolumn{2}{|c|}{} & Labour & GDP & Public capital & Private capital \\
\hline \multirow{2}{*}{ Response of labour to } & 0.005 & 3 & 1 & 1 & 1 \\
\cline { 2 - 6 } & 0.001 & 5 & 4 & 6 & 5 \\
\hline \multirow{2}{*}{ Response of GDP to } & 0.005 & 1 & 2 & 1 & 1 \\
\cline { 2 - 6 } & 0.001 & 5 & 3 & 1 & 8 \\
\hline \multirow{2}{*}{ Response of public capital to } & 0.005 & 6 & 4 & 3 & 4 \\
\cline { 2 - 6 } & 0.001 & 9 & 5 & 5 & 6 \\
\hline \multirow{2}{*}{ Response of private capital to } & 0.005 & 5 & 1 & 4 & 5 \\
\cline { 2 - 6 } & 0.001 & 10 & 3 & 4 & 8 \\
\hline
\end{tabular}



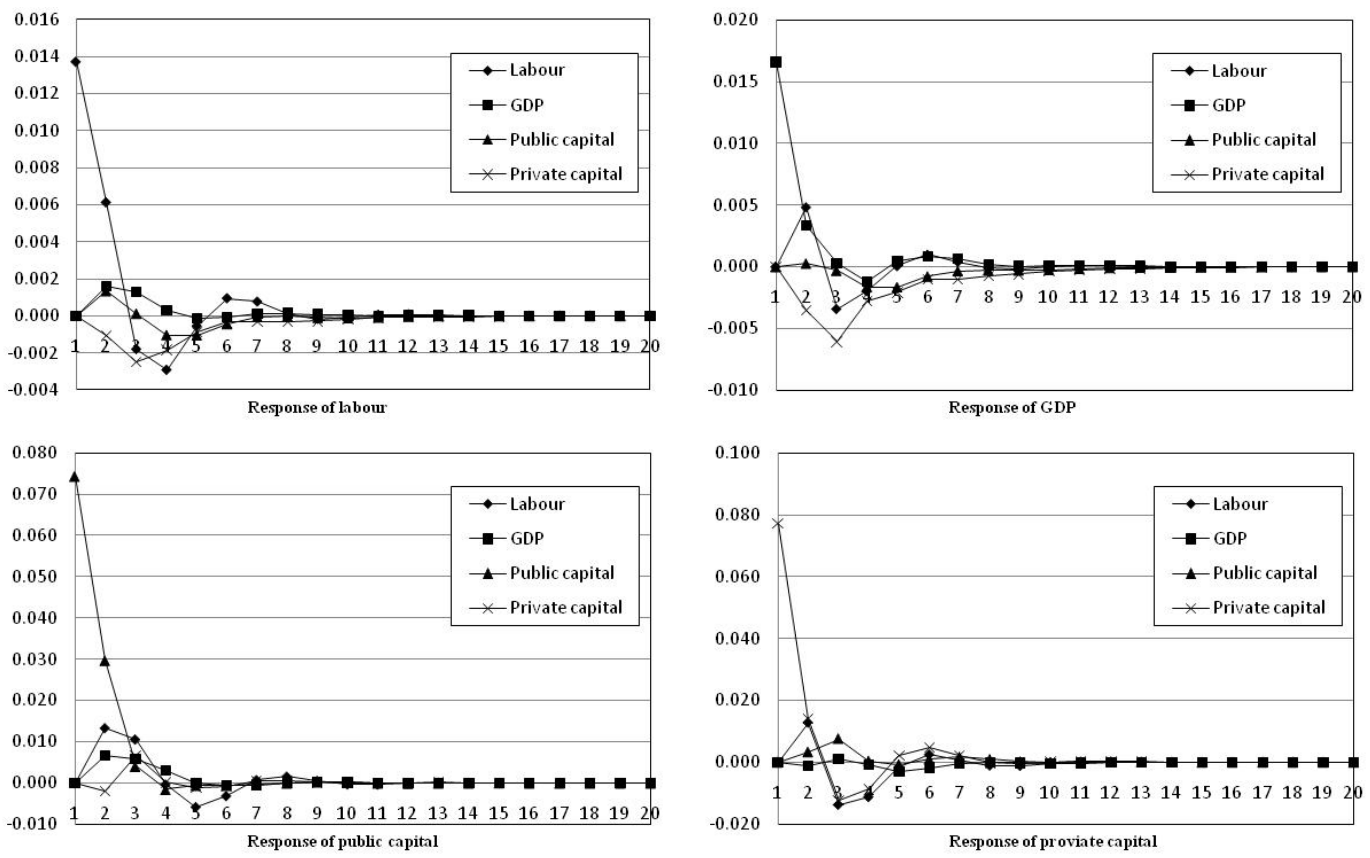

Figure 1. Response of one economic variable to others
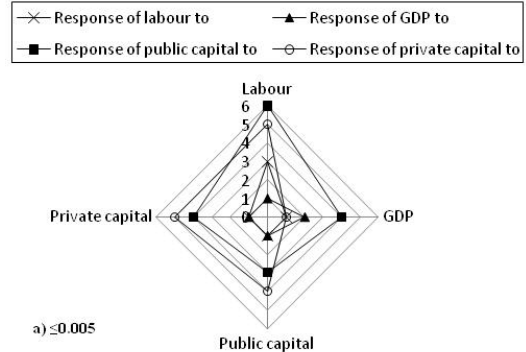
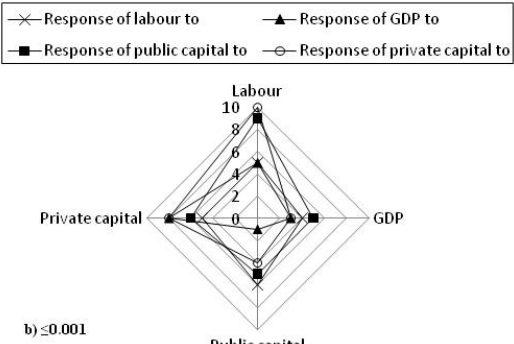

Figure 2. Lagged term when first reaching \pm 0.01 and \pm 0.005 intervals of impulse response
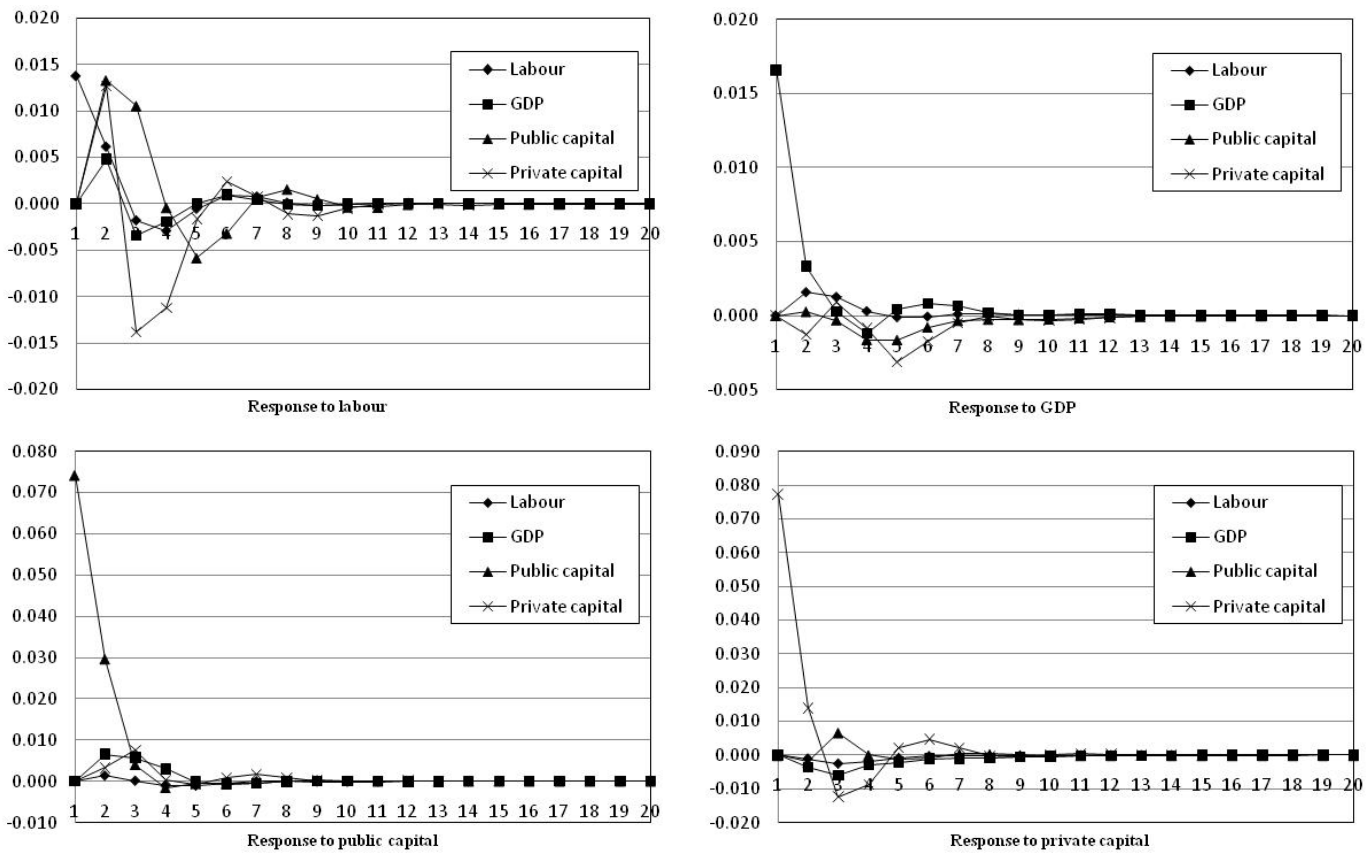

Figure 3. Effects of economic variable to others 